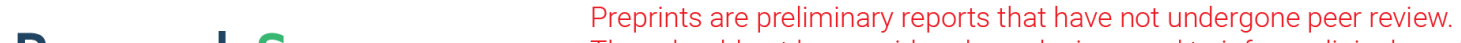 They should not be considered conclusive, used to inform clinical practice, or referenced by the media as validated information. \\ Modeling and Optimization of Weld Bead Profile with Varied Welding Stages for Weathering Steel A606
}

\section{Dawei Zhao ( $\nabla$ chzhaod@susu.ru )}

South Ural State University https://orcid.org/0000-0002-3865-2958

\section{Yuriy Bezgans}

Xi'an Jiaotong University

\section{Nikita Vdonin}

South Ural State University

\section{Liudmila Radionova}

South Ural State University

\section{Vitaly Bykov}

South Ural State University

\section{Research Article}

Keywords: operating parameters, weld bead profile, mechanical properties, gas metal arc welding

Posted Date: May 25th, 2021

DOI: https://doi.org/10.21203/rs.3.rs-500999/v1

License: (c) (1) This work is licensed under a Creative Commons Attribution 4.0 International License. Read Full License

Version of Record: A version of this preprint was published at The International Journal of Advanced Manufacturing Technology on July 19th, 2021. See the published version at https://doi.org/10.1007/s00170-021-07722-y. 


\title{
Modeling and optimization of weld bead profile with varied welding stages for weathering steel A606
}

\author{
Dawei Zhao $^{1,2} * \quad$ Yuriy Bezgans $^{1 *} \quad$ Nikita Vdonin $^{1} \quad$ Liudmila Radionova $^{3} \quad$ Vitaly \\ Bykov $^{3}$
}

( ${ }^{1}$ Department of Welding Engineering, Institution of Engineering and Technology, South Ural

State University, Chelyabinsk 454080, Russia;

${ }^{2}$ State Key Laboratory for Strength and Vibration of Mechanical Structures, Xi' an Jiaotong

University, Xi' an 710054, China;

${ }^{3}$ Department of Metal Forming, Institution of Engineering and Technology, South Ural State University, Chelyabinsk 454080, Russia)

Abstract: The profile of the welding bead changes with the welding process parameters during the gas metal arc welding (GMAW) process, the reinforcement disappears and the penetration becomes sunken when the excessive welding heat input is applied. However, little research work is specially planned to cope with the studying of welding bead at these stages. A systematic studying of the relationships among the welding process variables and welding bead geometric features and optimization of the welding quality is presented. The influences of the welding technological parameters (voltage, welding speed, and wire feed speed) on the welding geometry were revealed and the models correlating them were established. The features of the weld bead geometry were composed of top reinforcement width, top reinforcement height, penetration depth, bottom reinforcement width, and bottom reinforcement height. By the desirability function approach, the recommendation of suitable welding parameters to meet the contradicting demands of multiple bead geometric features is fulfilled. The microstructure in different welding regions and mechanical performances of the welding joints produced by the verification test were also studied.

Keywords: operating parameters; weld bead profile; mechanical properties; gas metal arc welding

\section{Introduction}

As a typical arc welding technology, gas metal arc welding (GMAW) has been broadly used in various industrial fields. In order to enhance the welding efficiency, the welding robot is usually employed in the actual production line. The welding process parameters have a crucial role in determining and controlling the welding bead geometry, mechanical performances, macrostructure, and microstructure properties of the welding joints. In this case, the operation parameters have to be planned and designed in advance to guarantee the welding joints with good quality at the minimum cost. During the arc welding process, the welding parameters alter the welding heat input supplied to the welding zone, which in turn changes the metallurgical characteristics and geometric features of the welding joints [1]. It is believed that the mechanical performances of the welding joints are determined by the welding bead geometry which is formed by the solidification of the liquid material in the

\footnotetext{
*Corresponding author: bezgansyv@susu.ru (Yuriy Bezgans), chzhaod@susu.ru (Dawei Zhao).
} 
welding process. Nevertheless, welding is a fast and uneven heat cyclical process. Because of the complexity of the interaction effects between arc and material, it is very difficult to guarantee the quality of arc welding. In this case, some welding defects, such as porosity, crack, burning, and distortion may be generated in the welding zone. It is stated the welding bead shape predominates the mechanical performances and quality of the weld. Therefore, the welding technological parameters should be scheduled correctly and carefully to get the welding joints of high quality without any welding defects.

Some researchers have performed the related research work to obtain the desired welding bead through the models which correlate the welding process variables and geometric features of the weld bead. The design of experiments and analysis of variables (ANOVA) are the most numerously employed methods for defining the optimal combination of the welding parameters. Taguchi method is one kind of optimization schemes with extraordinary efficiency and strong reliability for different manufacturing processes. Meseguer-Valdenebro et al. [2] utilized the Taguchi experiments with three variables (power of the heat source, welding speed, and separation of the edges) and selected the height of the welding bead, welding bead width, the penetration depth, the perimeter of the weld bead, and the area of the welding bead as the welding bead geometric features. The effects of the three welding parameters on the welding quality were also investigated. It was implied that the welding speed had the utmost influence on the profile of the weld bead. Kumar and Singh [3] designed the welding experiments according to the Taguchi-based orthogonal array. Influences of welding current, voltage, and preheat temperature were studied. It was indicated that the preheat temperature was the most effective input parameter for the welding quality followed by welding current and voltage. Sailender et al. [4] used the voltage, wire feeding speed, welding speed, and torch-to-plate distance as the welding process parameters; while the dilution and the size of the heat-affected zone were utilized to express the welding quality. The grey relational analysis was employed to normalize and optimize the welding experimental results. The results implied that a high level of wire feeding rate, welding speed, and torch-to-plate distance as well as a low level of voltage could produce the welding bead with minimum heat-affected zone and high value of dilution. Saha and Majumder [5] investigated the effects of welding current, arc voltage, and electrode stick out on the geometry of weld bead. The geometric features included welding bead width, dilution, and welding bead hardness. The welding experiments were arranged according to the Taguchi method. The grey relational analysis and principal component analysis were utilized to decide the ideal welding operation parameters. The Taguchi method is able to find the optimal welding process parameters. But it has some weak points, it can only optimize the parameters at the specific points, the ranges between the points cannot be explored by the Taguchi method.

Multiple regression analysis can predict the welding quality in the whole range of the selected welding process parameters. Besides, it also can reveal the interaction effects of the welding settings on the welding quality indexes vividly. The optimization combinations of the 
welding technological parameters are also able to be figured out based on the regression models. Korra et al. [6] studied the effects of the welding settings (welding current, torch traveling speed, and arc gap) on the welding bead geometry (depth of penetration, area of penetration region, bead width, bead depth, heat-affected zone size, and aspect ratio). The welding experiments were arranged in the accordance with the central composite design. Meanwhile, the model expressing the relationship between the welding settings and welding bead geometric features was developed and the optimum welding parameters were achieved using the desirability approach. Martinez-Conesa et al. [7] employed the Box-Behnken experimental design method to determine the welding schedule and chosen the gas flow rate, welding speed, voltage, and torch position as the welding process parameters. The depth of the penetration, bead width, and overthickness were employed to present the welding quality. A couple of response surface models were created based on the welding experimental results; the welding bead geometry was optimized by the $\varepsilon$-constraint approach. The results indicated that a high value of gas flow rate, low values of wire feeding speed and voltage would result in the sound balances among the maximum penetration, minimum bead width, and overthickness. Sharma et al. [8] followed the central composite design to carry out the experiments for the GMAW of magnesium alloy. Different levels of wire feeding rate, welding speed, gas flow rate, and external magnetic field were selected; the direct and interaction effects of the welding parameters on the welding quality were studied according to the regression models. The optimum process parameters were finally obtained. In sharp contrast to the Taguchi method, the regression analysis, including the response surface methodology, has the capability of simulating the correlation between the welding settings and the selected welding quality indexes. But it usually can only study the process with linear and second-order regression models, if the process intended to explore is rather complicated, other methods should be employed.

Artificial-based algorithms have been employed in the welding field by some researchers because they have the capability of modeling quite complex nonlinear relationships between inputs and outputs. Moghaddam et al. [9] selected the welding speed, wire feeding speed, voltage, groove angle, and nozzle-work distance in the GMAW process as the inputs, while the welding bead penetration, bead height, bead width, and heat-affected zone width as the outputs. The proposed back propagation neural network was utilized to model the relationships between the inputs and outputs. After that, the established model was optimized by the particle swarm optimization algorithm. The proposed approaches were able to achieve welding joints that had good welding quality with a desired welding bead geometry and minimum heat-affected zone. Nalajam and Varadarajan [10] established the model to correlate the links between the welding settings and welding bead profile using the forward and reverse neural network models. Besides, the effects of the welding technological parameters, namely welding current, welding speed, arc length, the temperature on welding bead width, bead depth, reinforcement height, bead coefficient, and dilution were also investigated. Venkatarao [11] conducted the welding experiments using different levels of 
torch angle, welding current, wire feeding speed, and welding speed. The width and height of the welding bead were checked to describe the welding quality. The teaching-learning-based optimization technique was then utilized to get the optimum weld bead geometry and minimum power consumption. Sivasakthivel and Sudhakaran [12] developed the backpropagation neural network model to predict the welding bead geometric features, namely the depth of penetration, bead height, and bead width in the GMAW process for stainless steel plates. The welding experiments were arranged by changing the welding settings such as welding speed, welding current, welding nozzle angle, wire feeding speed, and shielding gas flow. It was noticed that the relative error between the predicted results and the experimental results was less than $4 \%$ and the correlation coefficient was 0.985 . Although artificial-based algorithms have super abilities in modeling quite complicated processes, they need much more data than other methods to proficiently train the model. Besides, choosing and setting the weights and coefficients of these algorithms are usually relying on experiences; no effective basic theory is available at present.

GMAW is a sophisticated fusion welding process that is commonly used in numerous industrial fields, such as shipbuilding, construction, and pipe manufacturing. Throughout the welding process, the welding bead profile changes, and the final welding bead size determines the mechanical performance of the weld bead [13]. As stated by Zhang et al. [14], the formation and stages of the welding bead with different welding process parameters include overflowing, matching, and inadequate. The welding bead profile changes from overflowing to inadequate as the welding heat input increases, the top reinforcement decreases while the bottom reinforcement increases from zero to a certain value simultaneously. However, most of the previous research only focuses on the characteristics of the welding bead without the bottom reinforcement, the correlations among the welding process variables and the geometric features of the welding bead with inadequate penetration and overlarge bottom reinforcement due to too much welding heat have not been revealed yet.

In this investigation, an intensive framework is planned to study the weld bead characteristics at the stages of matching and inadequate. The welding experiments were performed according to the Box-Behnken design method with a little bit of extreme welding parameters. The simulative links between the welding settings and the welding bead geometric characteristics were established using regression analysis. The models were then embedded into the desirability functions to search for the optimal welding process parameters with the consideration of multiple bead geometric variables. After that, the welding bead produced by the optimal welding settings was assessed and compared to the results attained via the models. This investigation schedules and recommends the suitable welding parameters to get the sound welding bead geometry beforehand. It is also planned to reduce the calculation time for measuring the welding bead in the rapid and intelligent welding process.

\section{Experimental detail}


All of the experimental trials were conducted on bare weathering steel A606 sheets companying with the filler wire 09G2S. Table 1 and Table 2 list the chemical compositions of these two materials. The dimension of the steel plates is $60 \times 50 \times 3 \mathrm{~mm}$. The diameter of the filler wire is $1.2 \mathrm{~mm}$. The base metal was joined as a butt welding joint whose gap between the two steel plates is $1.0 \mathrm{~mm}$.

Table 1. Chemical compositions (wt. \%) and mechanical properties of steel A606 type IV.

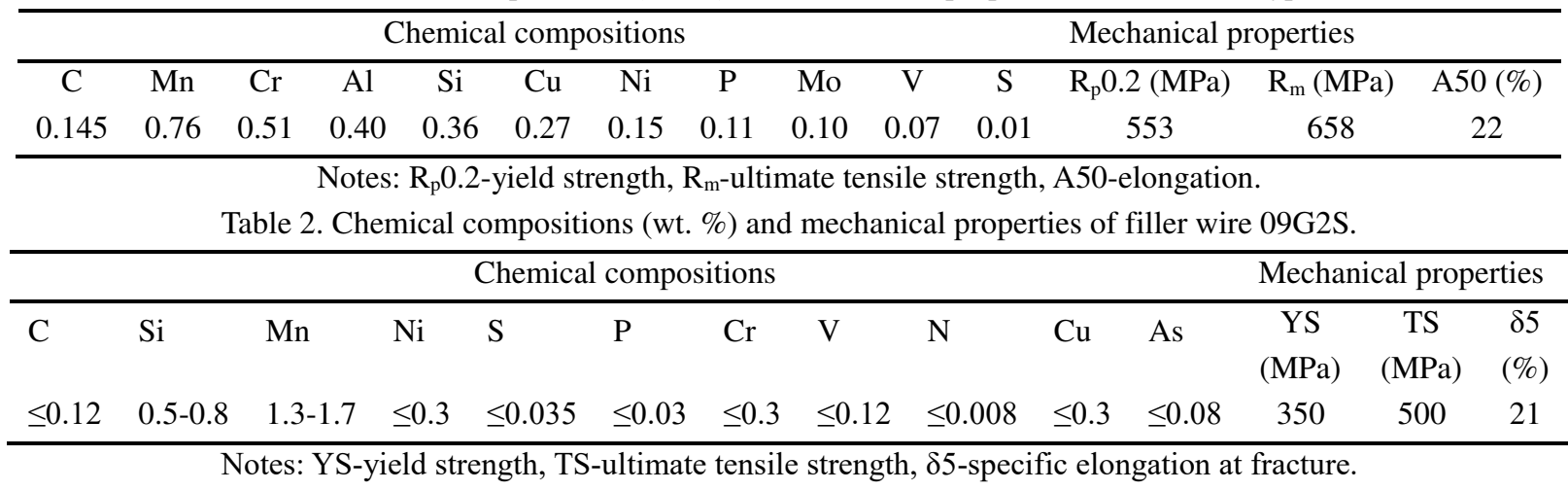

The process parameters are welding speed, voltage, and wire feeding speed. Among the welding process variables, the wire feed speed is directly proportional to the welding current [15]. Other welding parameters like the distance between nozzle and plate, gas flow rate, shielding gas ingredients, electrode angle are at constant values. The shielding gas is composed of $82 \% \mathrm{Ar}$ and $18 \% \mathrm{CO}_{2}$ with a flow of $20 \mathrm{~L} / \mathrm{min}$. The angle of the electrode is 90 degrees while the distance between the nozzle and the welding steel plates is $15 \mathrm{~mm}$. The ranges of the selected parameters were determined by several trial runs and visually checking the surface of the welding bead. The welding joints without any visible defects were finally selected. The upper and lower limitations of the levels for the welding parameters are specified in Table 3.

Table 3. Welding technological parameters and their accordance levels.

\begin{tabular}{cccccc}
\hline Parameters & Unit & Notation & \multicolumn{3}{c}{ Three levels } \\
\hline Voltage & $\mathrm{V}$ & $A$ & 15 & 16 & 17 \\
Wire feeding speed & $\mathrm{m} / \mathrm{min}$ & $B$ & 4 & 4.5 & 5 \\
Welding speed & $\mathrm{cm} / \mathrm{min}$ & $C$ & 25 & 35 & 45 \\
\hline
\end{tabular}

The design of the experimental method was applied to arrange the welding operations. The welding work was performed through a Fanuc GMAW robot with 5 freedoms, which is shown in Figure 1. After welding, the welding joints for each welding run were sliced into small sizes. They were then mounted into a cylinder with transparent silicone-based material. After that, the samples were ground and polished using SiC papers with grits from 240 to 4000. After further polishing using $0.5 \mu \mathrm{m}$ diamond paste, the samples were etched with $4 \%$ nitric acid to expose the welding zone. The etched welding bead was inspected using a low-magnification microscope, while the welding bead dimensions were measured by ImageJ software. The definitions of different welding bead geometric features are displayed in Figure 2. The results of the welding experiments are presented in Table 4. 


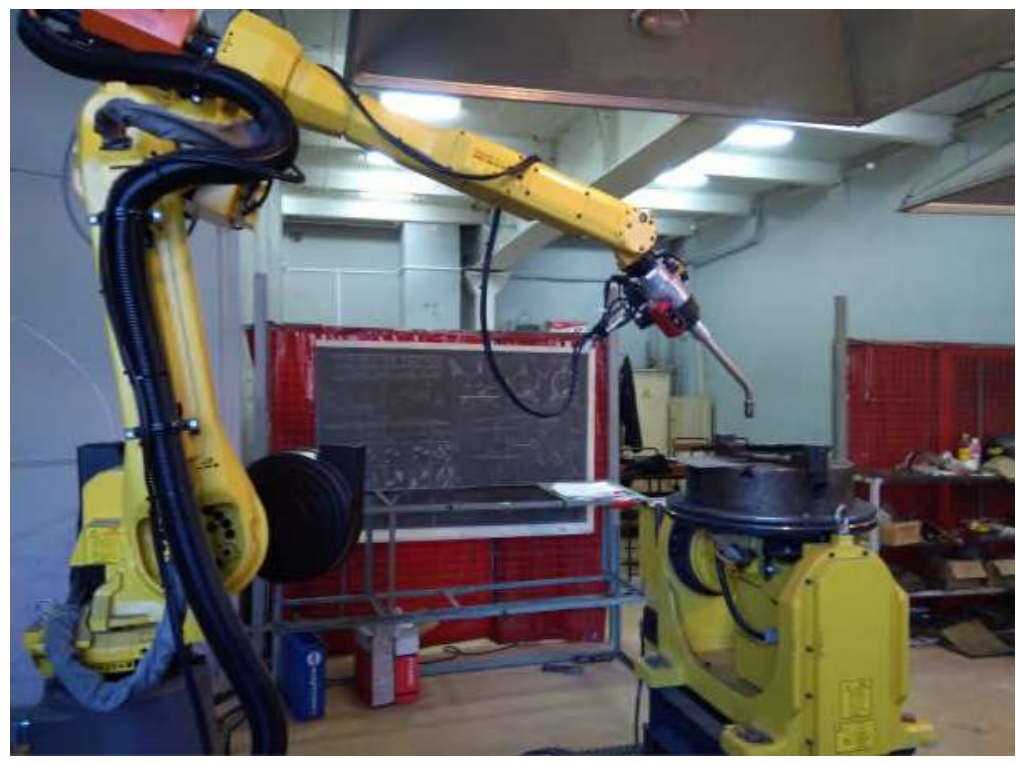

Figure 1. The welding machine employed in this investigation.

(a)

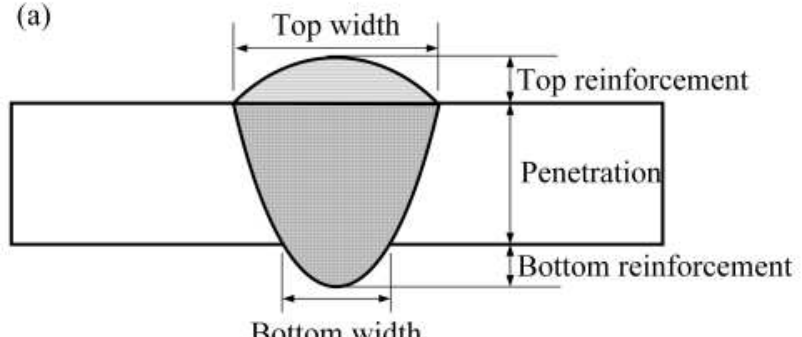

(b)

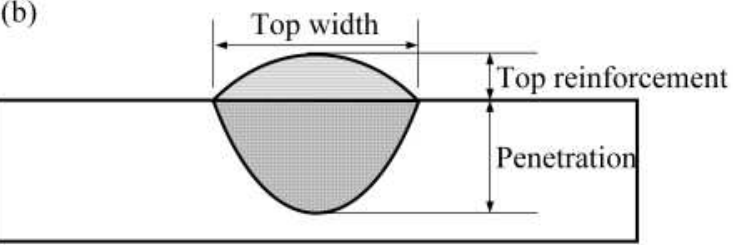

Figure 2. A typical welding bead (a) over-penetrated (b) insufficient-penetrated.

Table 4. The results of the welding experiments.

\begin{tabular}{|c|c|c|c|c|c|c|c|c|}
\hline $\begin{array}{c}\text { No } \\
\text {. }\end{array}$ & $\begin{array}{c}\text { Voltag } \\
\mathrm{e}\end{array}$ & $\begin{array}{c}\text { Wire } \\
\text { feed } \\
\text { speed } \\
B \\
\mathrm{~m} / \mathrm{mi} \\
\mathrm{n}\end{array}$ & $\begin{array}{c}\text { Weldin } \\
\text { g speed } \\
C \\
\mathrm{~cm} / \mathrm{min}\end{array}$ & $\begin{array}{c}\text { Upper } \\
\text { reinforcemen } \\
\text { t width } \\
W_{l} \\
\mathrm{~mm}\end{array}$ & $\begin{array}{c}\text { Upper } \\
\text { reinforcemen } \\
\text { t height } \\
R_{l} \\
\mathrm{~mm}\end{array}$ & $\begin{array}{c}\text { Penetratio } \\
\text { n depth } \\
P \\
\text { mm }\end{array}$ & $\begin{array}{c}\text { Bottom } \\
\text { reinforcemen } \\
\text { t width } \\
W_{2} \\
\mathrm{~mm}\end{array}$ & $\begin{array}{c}\text { Bottom } \\
\text { reinforcemen } \\
\text { t depth } \\
R_{2} \\
\mathrm{~mm}\end{array}$ \\
\hline 1 & 15 & 4 & 35 & 5.46 & 1.86 & 3.00 & 2.27 & 1.70 \\
\hline 2 & 17 & 4 & 35 & 5.32 & 1.72 & 3.00 & 2.42 & 0.93 \\
\hline 3 & 15 & 5 & 35 & 5.75 & 1.17 & 3.00 & 2.77 & 2.71 \\
\hline 4 & 17 & 5 & 35 & 5.31 & 1.78 & 3.00 & 2.52 & 1.37 \\
\hline 5 & 15 & 4.5 & 25 & 5.87 & -0.37 & 2.63 & 4.12 & 3.08 \\
\hline 6 & 17 & 4.5 & 25 & 4.48 & 0.45 & 3.00 & 5.27 & 3.37 \\
\hline 7 & 15 & 4.5 & 45 & 4.93 & 2.11 & 2.50 & 0.00 & 0.00 \\
\hline 8 & 17 & 4.5 & 45 & 4.96 & 1.79 & 3.00 & 1.72 & 0.72 \\
\hline 9 & 16 & 4 & 25 & 5.23 & 1.17 & 3.00 & 4.01 & 3.41 \\
\hline 10 & 16 & 5 & 25 & 4.96 & -0.51 & 2.49 & 4.82 & 4.43 \\
\hline 11 & 16 & 4 & 45 & 4.85 & 1.44 & 2.37 & 0.00 & 0.00 \\
\hline 12 & 16 & 5 & 45 & 4.99 & 2.11 & 3.00 & 1.79 & 1.70 \\
\hline 13 & 16 & 4.5 & 35 & 5.40 & 2.19 & 3.00 & 1.75 & 1.70 \\
\hline 14 & 16 & 4.5 & 35 & 5.26 & 1.51 & 3.00 & 3.24 & 3.48 \\
\hline 15 & 16 & 4.5 & 35 & 5.37 & 1.21 & 3.00 & 2.65 & 2.38 \\
\hline 16 & 16 & 4.5 & 35 & 5.42 & 1.87 & 3.00 & 1.67 & 0.71 \\
\hline
\end{tabular}


$\begin{array}{lcccc}17 & 16 & 4.5 & 35 & 5.48\end{array}$

The calculation and analysis of the GMAW process parameters of weathering steel A 606 were carried out using the software of Design Expert 12.0. The least-square method was made use of to obtain the coefficients of the regression models quantifying the functional relationships among the welding process variables and welding bead geometric characteristics. Assuming the welding bead shape variable is $y_{i}$, while a certain welding process parameter variable is $x_{i}$, the relations between the inputs and outputs can be expressed using different polynomial functions. The quadratic polynomial function is usually employed and its expression is listed as follows,

$$
y_{i}=\alpha_{0}+\sum_{i=1}^{n} \alpha_{i} x_{i}+\sum_{i=1, j=1, i \neq j}^{n} \alpha_{i j} x_{i} x_{j}+\sum_{i=1}^{n} \alpha_{i i} x_{i}^{2}
$$

where $\alpha_{0}$ is the constant term, $\alpha_{i}$ are the linear coefficients, $\alpha_{i i}$ are the ones for the quadratic terms, while $\alpha_{i j}$ indicate the coefficients for the interaction effects of the welding settings. All the coefficients can be achieved by the least square method.

The analysis of variance (ANOVA) approach was utilized to check the adequacy and reliability of the developed model at a 95\% significance level. A P-value with a level of less than 0.05 implies that the established model is quite significant. The significances of all the terms in the models are also checked by their P-values. The critical P-value is 0.1 , if the value is larger than 0.1 , it means that this accordance item is non-significant to the entire regression model [16]. In this case, this item should be discarded. The value of lack of fit is similarly helpful since it can also inspect the significance test of the model. Its value should be larger than 0.1 and as large as possible. The adequacy measurement of the variable $R^{2}$ is in the range of 0 and 1 , it should be adjacent to 1 and as large as possible. In addition, the differences among the levels of $R^{2}$, Adjusted $R^{2}$, and Predicted $R^{2}$ should be within 0.2 and as little as possible. The index of adequate precision ratio is a variable standing for the signal-to-noise ratio, which is desired to be larger than 4 . The ANOVA results of the welding bead geometric features are exhibited in Table 5, Table 6, Table 7, Table 8, and Table 9.

Table 5. The results of the ANOVA for the top reinforcement width.

\begin{tabular}{ccccccc}
\hline Source & Sum of squares & df & Mean square & F-value & P-value & \\
\hline Model & 1.68 & 4 & 0.4212 & 24.08 & $<0.0001$ & significant \\
$A$ & 0.4705 & 1 & 0.4704 & 26.89 & 0.0002 & \\
$C$ & 0.0820 & 1 & 0.0820 & 4.69 & 0.0512 & \\
$A C$ & 0.5041 & 1 & 0.5041 & 28.82 & 0.0002 & \\
$C^{2}$ & 0.6282 & 1 & 0.6282 & 35.91 & $<0.0001$ & \\
Residual & 0.2099 & 12 & 0.0175 & & & \\
Lack of Fit & 0.1836 & 8 & 0.0229 & 3.49 & 0.1214 & not significant \\
Pure Error & 0.0263 & 4 & 0.0066 & & & \\
Cor Total & 1.89 & 16 & & & & \\
\hline
\end{tabular}

Notes: Standard deviation $=0.1323$, Mean $=5.24, R^{2}=0.8892$, Adjusted $R^{2}=0.8523$, Predicted $R^{2}=0.6976$, Adeq Precision=16.6601, Coefficient of variation $(\%)=2.53$.

Table 6. The results of the ANOVA for the top reinforcement height. 


\begin{tabular}{ccccccc}
\hline Source & Sum of squares & df & Mean square & F-value & P-value & \\
\hline Model & 9.26 & 4 & 2.31 & 20.70 & $<0.0001$ & significant \\
$B$ & 0.3362 & 1 & 0.3362 & 3.01 & 0.1085 & \\
$C$ & 5.63 & 1 & 5.63 & 50.33 & $<0.0001$ & \\
$B C$ & 1.38 & 1 & 1.38 & 12.35 & 0.0043 & \\
$C^{2}$ & 1.91 & 1 & 1.91 & 17.10 & 0.0014 & \\
Residual & 1.34 & 12 & 0.1118 & & & \\
Lack of Fit & 0.7447 & 8 & 0.0931 & 0.6235 & 0.7363 & not significant \\
Pure Error & 0.5971 & 4 & 0.1493 & & & \\
Cor Total & 10.60 & 16 & & & & \\
\hline
\end{tabular}

Notes: Standard deviation $=0.3344$, Mean $=1.38, R^{2}=0.8734$, Adjusted $R^{2}=0.8312$, Predicted $R^{2}=0.7723$, Adeq

Precision $=15.7296$, Coefficient of variation $(\%)=24.24$.

Table 7. The results of the ANOVA for the penetration depth.

\begin{tabular}{ccccccc}
\hline Source & Sum of squares & df & Mean square & F-value & P-value & \\
\hline Model & 0.6965 & 5 & 0.1393 & 13.96 & 0.0002 & significant \\
$A$ & 0.0946 & 1 & 0.0946 & 9.48 & 0.0105 & \\
$B$ & 0.0018 & 1 & 0.0018 & 0.1804 & 0.6792 & \\
$C$ & 0.0078 & 1 & 0.0078 & 0.7829 & 0.3952 & \\
$B C$ & 0.3249 & 1 & 0.3249 & 32.56 & 0.0001 & \\
$C^{2}$ & 0.2674 & 1 & 0.2674 & 26.79 & 0.0003 & \\
Residual & 0.1098 & 11 & 0.01 & & & \\
Lack of Fit & 0.1098 & 7 & 0.0157 & & & \\
Pure Error & 0 & 4 & 0 & & & \\
Cor Total & 0.8062 & 16 & & & & \\
\hline
\end{tabular}

Notes: Standard deviation=0.0999, Mean $=2.88, R^{2}=0.8639$, Adjusted $R^{2}=0.8020$, Predicted $R^{2}=0.6272$, Adeq Precision=11.9008, Coefficient of variation $(\%)=3.47$.

Table 8 . The results of the ANOVA for the bottom reinforcement width.

\begin{tabular}{ccccccc}
\hline Source & Sum of squares & df & Mean square & F-value & P-value & \\
\hline Model & 28.33 & 2 & 14.16 & 38.36 & $<0.0001$ & significant \\
$B$ & 1.28 & 1 & 1.28 & 3.47 & 0.0837 & \\
$C$ & 27.05 & 1 & 27.05 & 73.26 & $<0.0001$ & \\
Residual & 5.17 & 14 & 0.3692 & & & \\
Lack of Fit & 3.46 & 10 & 0.3465 & 0.8134 & 0.6415 & not significant \\
Pure Error & 1.7 & 4 & 0.426 & & & \\
Cor Total & 33.5 & 16 & & & & \\
\hline
\end{tabular}

Notes: Standard deviation $=0.6076$, Mean $=2.55, R^{2}=0.8457$, Adjusted $R^{2}=0.8237$, Predicted $R^{2}=0.7800$, Adeq Precision $=17.5418$, Coefficient of variation $(\%)=23.81$.

Table 9. The results of the ANOVA for the bottom reinforcement depth.

\begin{tabular}{ccccccc}
\hline Source & Sum of squares & df & Mean square & F-value & P-value & \\
\hline Model & 19.79 & 2 & 9.89 & 19.33 & $<0.0001$ & significant \\
$B$ & 2.17 & 1 & 2.17 & 4.25 & 0.0584 & \\
$C$ & 17.61 & 1 & 17.61 & 34.41 & $<0.0001$ & \\
Residual & 7.17 & 14 & 0.5119 & & & \\
Lack of Fit & 3.07 & 10 & 0.3069 & 0.2996 & 0.9444 & not significant \\
Pure Error & 4.1 & 4 & 1.02 & & & \\
Cor Total & 26.95 & 16 & & & & \\
\hline
\end{tabular}

Notes: Standard deviation $=0.7154$, Mean $=2.00, R^{2}=0.7341$, Adjusted $R^{2}=0.6961$, Predicted $R^{2}=0.6400$, Adeq 
Precision=13.3423, Coefficient of variation $(\%)=35.84$.

Based on the ANOVA analysis results, the studied welding process parameters, namely welding speed, wire feeding speed, and voltage have non-neglected effects on the welding bead shape and dimensions. Voltage and welding speed have non-neglected effects on the upper reinforcement width; while the wire feeding speed and welding speed affect the upper reinforcement height. The depth of the penetration is determined by the wire feeding speed and welding speed, so do bottom width and reinforcement. After the ANOVA analysis and the stepwise regression process, the models linking the welding technological parameters and welding bead geometric features were obtained and listed as follows,

$$
\begin{gathered}
W_{l}=24.8153-1.4850 \times A-0.3085 \times C+0.0355 \times A C-0.0039 \times C^{2} \\
R_{l}=10.8816-4.5225 \times B+0.0254 \times C+0.1175 \times B C-0.00672 \times C^{2} \\
P=7.1341+0.1088 \times \mathrm{A}-1.965 \times B-0.0838 \times C+0.057 \times B C-0.0025 \times C^{2} \\
W_{2}=5.3880+0.8 \times B-0.1839 \times C \\
R_{2}=2.4983+1.0403 \times B-0.1484 \times C
\end{gathered}
$$

where

$$
\begin{gathered}
15 \mathrm{~V} \leq A \leq 17 \mathrm{~V} \\
4 \mathrm{~m} / \mathrm{min} \leq B \leq 5 \mathrm{~m} / \mathrm{min} \\
25 \mathrm{~cm} / \mathrm{min} \leq C \leq 45 \mathrm{~cm} / \mathrm{min}
\end{gathered}
$$

After obtaining the regression models, the effects and interaction effects of the welding technological parameters on the welding bead geometry can be obtained via the developed models. The following section is intended to deal with the effects and interaction effects of the welding process settings on the welding bead geometries.

\section{Results and discussion}

\subsection{Effects of the welding variables on the welding bead geometric characteristics}

The effects of voltage and welding speed on the top reinforcement width are displayed in Figure 3. Generally, it has been found that the top reinforcement is mainly determined by the wetting of the molten area through the welding material and the region influenced by the moving arc nozzle [15]. Based on the developed model, the upper reinforcement width is affected by the factors of welding speed and voltage. As the voltage increases from 15 to 17 $\mathrm{V}$ and the welding speed is kept at the level of $45 \mathrm{~cm} / \mathrm{min}$, the width of the upper reinforcement rises with a magnitude of about $0.3 \mathrm{~mm}$. It is believed that increasing the voltage brings about the upward width of the welding arc cone. With the increase of arc voltage, the force of conventional current increases, the arc length increases, the plasma velocity increases, the arc cone deflects outward, the arc cone becomes wider. All the chain reactions lead to an increase in the width of the upper reinforcement. However, the top reinforcement width decreases with the voltage when the value of welding speed is 25 $\mathrm{cm} / \mathrm{min}$. It seems to be completely contradictory with the conclusions obtained by other researchers [17]. The reason will be revealed together with the discussion of the influence of welding speed.

The top reinforcement width roughly decreases with the levels of the torch travel speed 
as the voltage is kept at $15 \mathrm{~V}$ in Figure 3 (b), which is in keeping with the previous studies. The welding heat input becomes lower and less molten material will deposit into the welding pool when the torch travel speed starts to go faster, which in turn results in a decreased upper reinforcement width of the welding bead. Nevertheless, the top reinforcement width firstly increases with the welding speed until it gets to its peak point; afterward, it decreases with the welding speed when the voltage is $17 \mathrm{~V}$, as displayed in Figure 3 (b). This behavior seems to be against Chandrasekaran's research work [15]. According to Zhang et al. [14], the melting speed of base metal is less than that of filler wire when the welding current is at its lower level; in this case, more molten filler wire is deposited on the surface of the welding pool, which makes up of the reinforcement. As the welding current gets larger, the melting rate of the base metal is faster than that of the feeding wire; in this case, the welding pool can accommodate more melted feeding wire, which in turn gives rise to less melted feeding wire overflowing the welding pool. As slower welding speed means more welding heat can be transferred to the welding zone, the melting speed of base metal is faster than that of the filler wire, the welding bead width decreases with the decreasing welding speed. After the critical point (when the melting speed of the base metal balances the filler wire's melting speed), the welding bead decreases with the increasing welding speed.
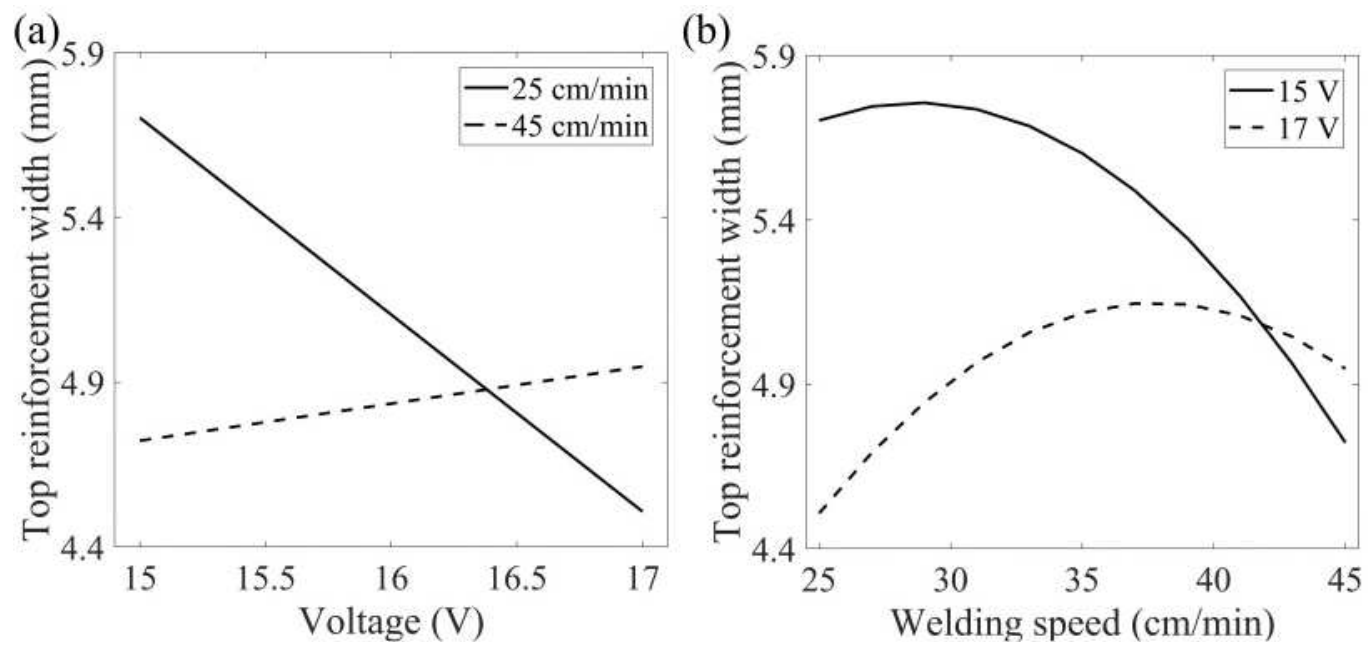

Figure 3. The effects of voltage and welding speed on the top reinforcement width $(B=4.5 \mathrm{~m} / \mathrm{min})$.

As for the height of the top reinforcement, it increases with the wire feed speed while the welding speed is $45 \mathrm{~cm} / \mathrm{min}$, while it decreases with the same factor as the arc torch traveling speed is at its level of $25 \mathrm{~cm} / \mathrm{min}$, as presented in Figure 4. When the melted wire is deposited onto the surface of the base metal which produces a layer of reinforcement, it is apparent that the top reinforcement height of all welds increases when the wire feeding speed increases from $4 \mathrm{~m} / \mathrm{min}$ to $5 \mathrm{~m} / \mathrm{min}$, so the wire feeding speed factor presents a positive effect when the welding arc moving speed is $45 \mathrm{~cm} / \mathrm{min}$. However, the height of top reinforcement decreases with the wire feed speed as the welding speed is $25 \mathrm{~cm} / \mathrm{min}$. Because low arc torch moving speed and high wire feeding speed means the welding heat input is huge. In this case, the top reinforcement will grow flat and even become sunken owing to excessive welding heat input and the interactive influences of the related factors. It is not unexpected to note that the height of reinforcement becomes minus when the welding speed is at the value of 25 
$\mathrm{cm} / \mathrm{min}$, and the wire feeding speed is at its level of $5 \mathrm{~m} / \mathrm{min}$.
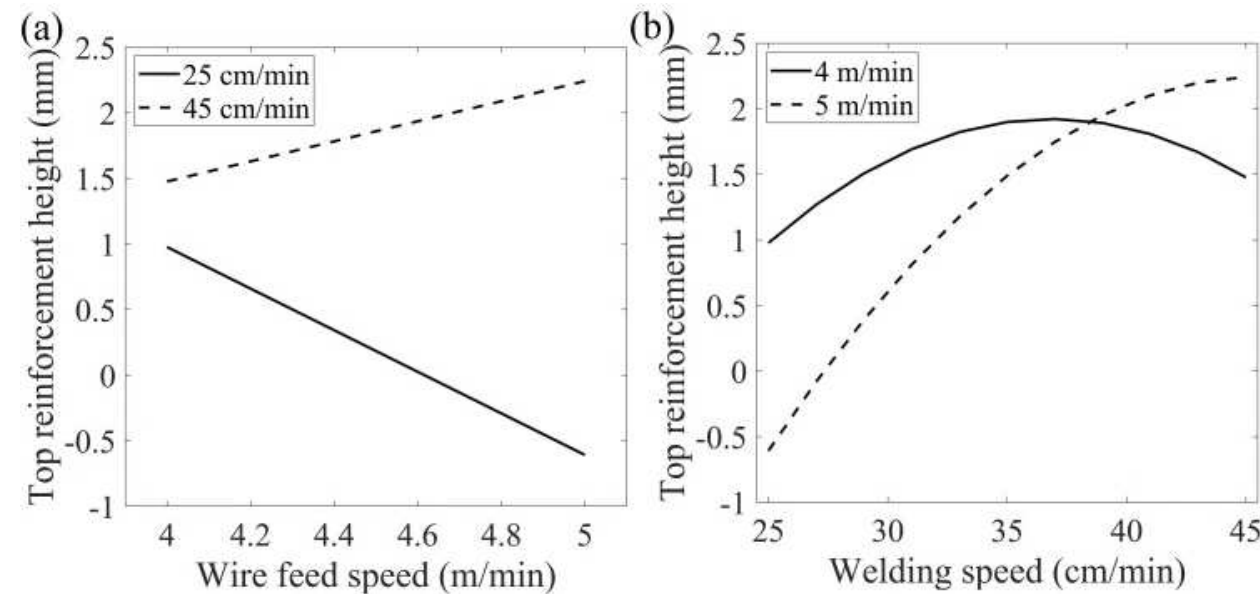

Figure 4. The effects of wire feed speed and welding speed on the top reinforcement height $(A=16 \mathrm{~V})$.

Figure 4 (b) displays the effect of welding speed on the top reinforcement height. It can be noted that the reinforcement height increases with the welding speed when the wire feeding speed is at its maximum level; while it firstly rises to its peak and then goes down when the wire feeding speed is at $4 \mathrm{~m} / \mathrm{min}$. It seems these trends are anti the previous studies once again [18]. The welding bead profile changes when the welding heat input varies. It is composed of three stages as the welding heat input increases, which are overflowing, matching, and inadequate. The conclusion that the upper reinforcement height decreases with the welding speed relies on the fact that the welding bead is in the overflowing and matching stages [14]. However, the welds in this investigation are in the stage of matching, and inadequate. During the matching stage, the welding heat is not overlarge; the top reinforcement is convex instead of being flat or sunken. So the higher welding speed indicates that less melted filler wire will be deposited into the welding pool per unit of time, in this case, the top reinforcement height decreases while the arc torch traveling speed gets faster. Regarding the stage of being inadequate, the reinforcement becomes flat or sunken when the welding heat input keeps on rising. It is why the reinforcement height continues to increase with the welding speed when the wire feeding speed is $5 \mathrm{~m} / \mathrm{min}$.

Figure 5 (b) demonstrates the effect of the wire feeding speed on the penetration depth at two extreme levels of welding speed. The penetration depth increases with the wire feeding speed while the welding speed is maximized, whereas it decreases when the torch traveling speed is at $25 \mathrm{~cm} / \mathrm{min}$. It can be concluded the fact that the welding bead belongs to the matching stage when the welding speed is at $45 \mathrm{~cm} / \mathrm{min}$. As for penetration, the Lorentz force is imperative in transferring welding heat from the wire to the welding pool by forcing the liquid deeper into the molten metal droplets. As the Lorentz force is the cross product of the welding current density vector and the magnetic flux vector, the welding current is the vital factor to control the penetration [15]. The greater the current density is, the larger the magnitude of the Lorentz force will be, thus allowing the weld to penetrate deeper. As the welding power employed in this investigation provides constant voltage, the wire feeding speed is positively proportional to the welding current; as a consequence, the penetration 
depth increases with the wire feeding speed. As the welding speed is $25 \mathrm{~cm} / \mathrm{min}$, the penetration depth decreases from $3 \mathrm{~mm}$ to about $2.5 \mathrm{~mm}$ with the increasing wire feeding speed. When the welding bead is at its inadequate stage, increasing wire feeding speed means more welding heat input. The reinforcement becomes flat and sunken, in this case, the penetration depth decreases and the dropping molten metal generates the bottom reinforcement. The penetration depth increases with the welding speed and then decreases regardless of the values of wire feeding speed, as displayed in Figure 5 (a). The reason behind this phenomenon is alike to that of the wire feed speed.
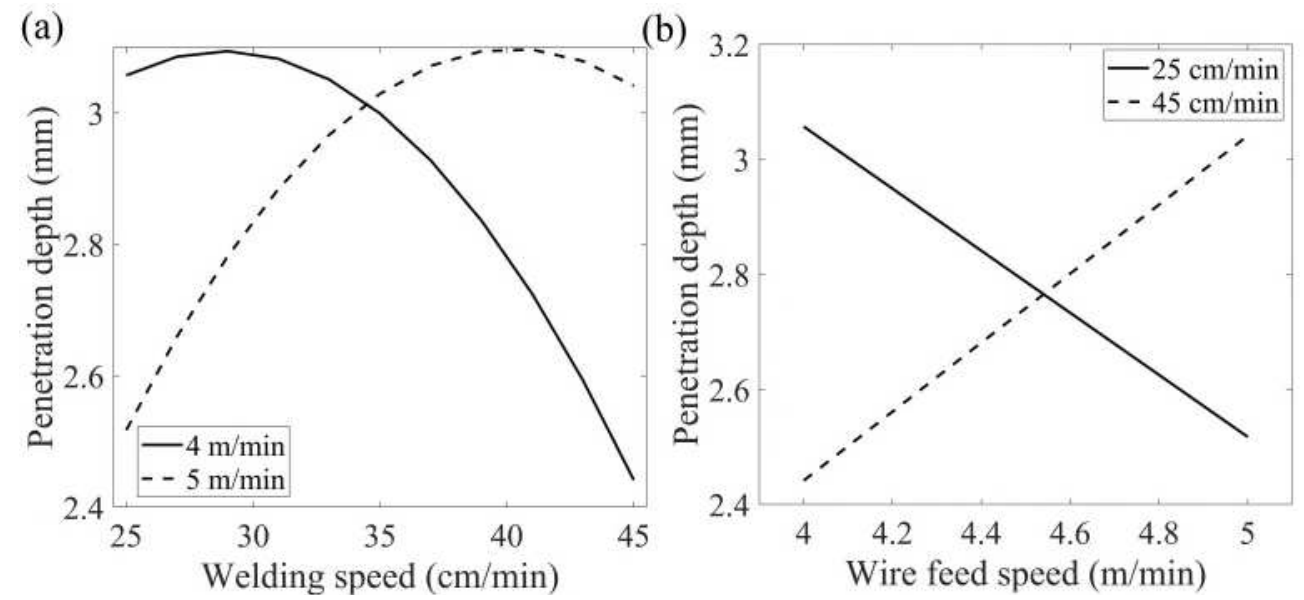

Figure 5. The effects of welding speed and wire feed speed on the penetration depth $(A=16 \mathrm{~V})$.

The effects of the welding speed on the width and height of the bottom reinforcement are negative, as shown in Figure 6 (a). Because the bottom reinforcement is produced by the effects of excessive welding heat input, the Lorentz force, and arc pressure. The top reinforcement turns to be flat and sunken; the excessive molten metal is forced to transfer across the welding pool and collapse, which results in the bottom reinforcement. Thus, it can be logically asserted that the bottom reinforcement is produced by too much welding heat. Under such circumstances, it is apparent that the width and height of the bottom reinforcement decrease with the welding speed while increase with the wire feeding speed (in Figure 6).
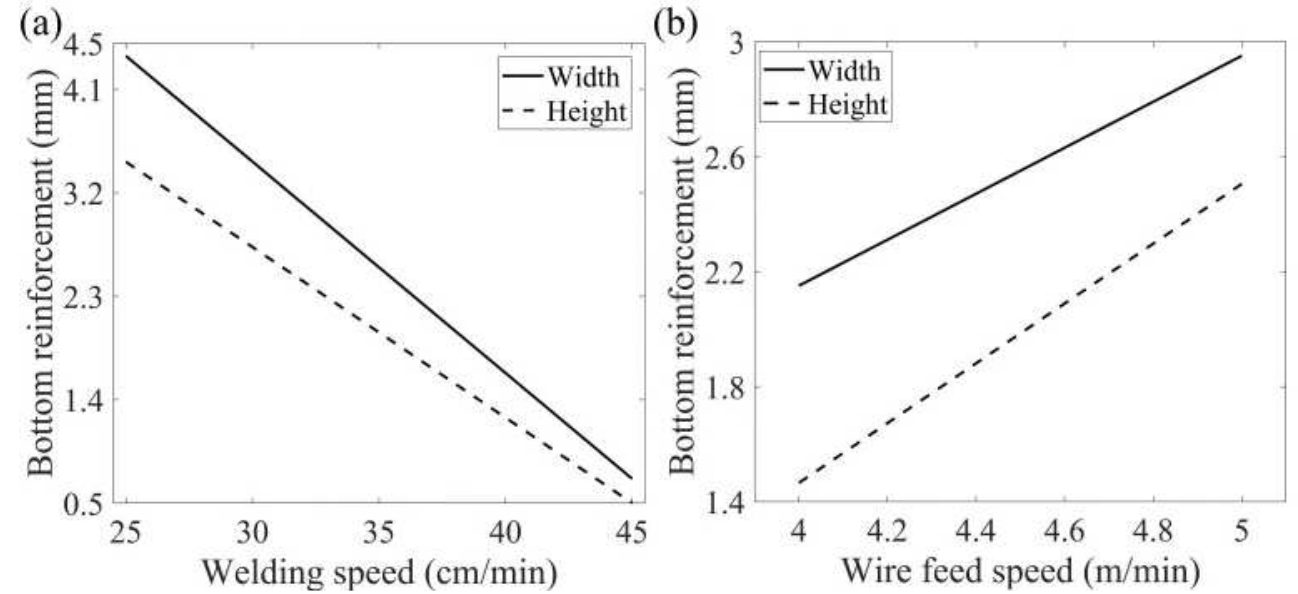

Figure 6. The effects of welding speed and wire feed speed on the bottom reinforcement size $(A=16 \mathrm{~V})$.

\subsection{Simultaneous improvements of the responses and verification test}


In this section, the geometric features of the weld bead should be optimized simultaneously. But it is a complex issue, because the different features may conflict with each other. The desirability function approach was employed to deal with the multiple response problems. This approach changes each geometric model into an individual desirability function whose range is in the interior zero to one. All the responses can be classified into three categories in terms of their objectives, they are the larger the better, the smaller the better, and the objective to a specific value. The individual desirability function of each geometric feature can be obtained based on the following equations [19]. As for the response belonging to the larger the better, the expression of the individual desirability function is shown as follows,

$$
d_{i}= \begin{cases}0 & y_{i}<y_{\text {min }} \\ \left(\frac{y_{i}-y_{\text {min }}}{y_{\text {max }}-y_{\text {min }}}\right)^{t} & y_{\text {min }} \leq y_{i} \leq y_{\text {max }} \\ 1 & y_{i}>y_{\text {max }}\end{cases}
$$

where $d_{i}$ is the individual desirability function of the response, $y_{i}$ is the response, $y_{\max }$ is the maximum value of this response, $y_{\min }$ is its minimum value, while $t$ denotes the shape index of the desirability function.

As for the response belonging to the smaller the better, its accordance individual desirability function is expressed as follows,

$$
d_{i}= \begin{cases}1 & y_{i}<y_{\min } \\ \left(\frac{y_{\text {max }}-y_{i}}{y_{\text {max }}-y_{\text {min }}}\right)^{t} & y_{\min } \leq y_{i} \leq y_{\max } \\ 0 & y_{i}>y_{\max }\end{cases}
$$

Once the individual desirability function of each response is obtained, the composite desirability function is calculated in the light of the following expression,

$$
D=d_{1}^{\omega_{1}} \times d_{2}^{\omega_{2}} \times \mathrm{L} \times d_{n}^{\omega_{n}}
$$

where $d_{i}$ is the individual desirability function, $\omega_{i}$ is its weight and the sum of them should be 1. The range of the composite desirability function is between 0 and 1 . As far as its value is concerned, the bigger the better. With the aim of acquiring the composite desirability function, the geometric features should be converted into their accordance individual desirability functions. The weld bead geometric characteristics and expressions of all the individual desirability functions are listed in Table 10.

Table 10. The settings of the geometric variables.

\begin{tabular}{ccccccc}
\hline Variable & Goal & $\begin{array}{c}\text { Lower limit } \\
(\mathrm{mm})\end{array}$ & $\begin{array}{c}\text { Upper limit } \\
(\mathrm{mm})\end{array}$ & $\begin{array}{c}\text { Weight (shape } \\
\text { index })\end{array}$ & $\begin{array}{c}\text { Importance } \\
\text { Individual desirability } \\
\text { function }\end{array}$ \\
\hline$W_{l}$ & Minimize & 4.48 & 5.87 & 1 & 3 & $d_{1}=\frac{5.87-W_{1}}{5.87-4.48}$ \\
$R_{l}$ & Minimize & -0.51 & 2.19 & 1 & 3 & $2.19-R_{1}$ \\
& & & & & $d_{2}=\frac{2.19-(-0.51)}{2}$
\end{tabular}




\begin{tabular}{ccccccc}
$P$ & Maximum & 2.37 & 3.00 & 1 & 3 & $d_{3}=\frac{P-2.37}{3-2.37}$ \\
$W_{2}$ & Minimize & 0.00 & 5.27 & 1 & 3 & $d_{4}=\frac{5.27-W_{2}}{5.27-0}$ \\
$R_{2}$ & Minimize & 0.00 & 4.43 & 1 & 3 & $d_{5}=\frac{4.43-R_{2}}{4.43-0}$ \\
\hline
\end{tabular}

Once the composite desirability function is achieved according to Equation (10), a suitable optimization approach should be employed to find the optimal welding process parameters. In this investigation, a numerical optimization method was used and the optimization process was performed using the software Design Expert 12.0. Table 11 exhibits the best welding parameters, the value of composite desirability function, and predicted values of all the responses. As witnessed by the results in Table 11, the optimal welding process parameters are voltage of $17 \mathrm{~V}$, wire feeding speed of $4.26 \mathrm{~m} / \mathrm{min}$, welding speed of $45 \mathrm{~cm} / \mathrm{min}$, while the predicted values of the geometric features are top reinforcement width of $5.05 \mathrm{~mm}$, top reinforcement height of $1.68 \mathrm{~mm}$, penetration depth of $2.68 \mathrm{~mm}$, the values of bottom reinforcement width and height are $0.52 \mathrm{~mm}$ and $0.26 \mathrm{~mm}$.

Table 11. The optimized welding process parameters obtained by the software of the Design Expert 12.0.

\begin{tabular}{|c|c|c|c|c|c|c|c|c|c|c|}
\hline No. & $\begin{array}{l}A \\
\mathrm{~V}\end{array}$ & $\begin{array}{c}B \\
\mathrm{~m} / \mathrm{min}\end{array}$ & $\begin{array}{c}C \\
\mathrm{~cm} / \mathrm{min}\end{array}$ & $\begin{array}{l}W_{l} \\
\mathrm{~mm}\end{array}$ & $\begin{array}{c}R_{l} \\
\mathrm{~mm}\end{array}$ & $\begin{array}{c}P_{1} \\
\mathrm{~mm}\end{array}$ & $\begin{array}{l}W_{2} \\
\mathrm{~mm}\end{array}$ & $\begin{array}{c}R_{2} \\
\mathrm{~mm}\end{array}$ & $\begin{array}{c}\text { Desirability value } \\
-\end{array}$ & $\begin{array}{l}\text { Remarks } \\
\text { - }\end{array}$ \\
\hline 1 & 17 & 4.261 & 45 & 5.05 & 1.68 & 2.68 & 0.52 & 0.26 & 0.543 & Selected \\
\hline 2 & 17 & 4.256 & 44.999 & 5.05 & 1.68 & 2.68 & 0.52 & 0.26 & 0.543 & \\
\hline 3 & 17 & 4.229 & 45 & 5.05 & 1.65 & 2.66 & 0.50 & 0.23 & 0.543 & \\
\hline 4 & 16.975 & 4.269 & 45 & 5.04 & 1.69 & 2.69 & 0.53 & 0.27 & 0.542 & \\
\hline 5 & 16.974 & 4.251 & 45 & 5.04 & 1.67 & 2.67 & 0.51 & 0.25 & 0.542 & \\
\hline
\end{tabular}

With the intention of validating the reliability, correctness, and applicability of the optimization method, the confirmation experiment should be performed using the optimal welding process parameters. The macrostructure, mechanical properties, and microstructural parameters of the welding joints are produced by the optimal welding process parameters. Figure 7 shows the welding joints. No such welding defects like cracks, small voids, and slag inclusions are visually inspected. Figure 8 displays the microstructure of the welding joints. The base metal consists of pearlite and proeutectoid ferrite. It seems that the basic phases of the fine-grained heat-affected zone are also ferrite and pearlite, but the grain sizes are much finer. Bainite, pearlite, and ferrite are detected in the heat affected zone of coarse grains. Although the welding process experiences a high cooling rate, no martensite was found in this region. The probable reason may be the fact the base metal contains a low percentage of carbon [20]. The phases of the welding zone are acicular ferrite, and grain boundary ferrite. 


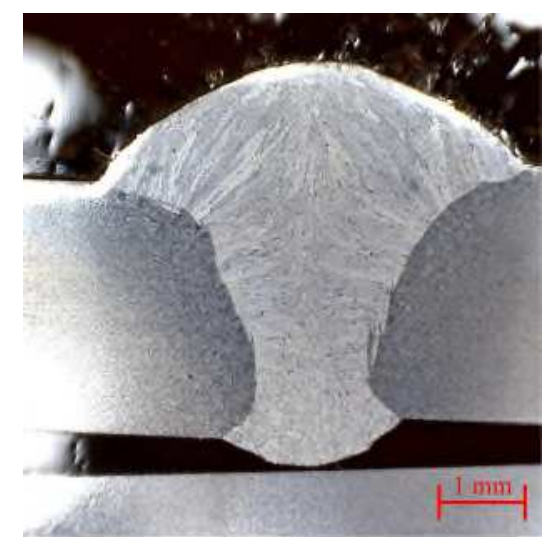

Figure 7. The macrostructure of the welding joints obtained by the verification test.

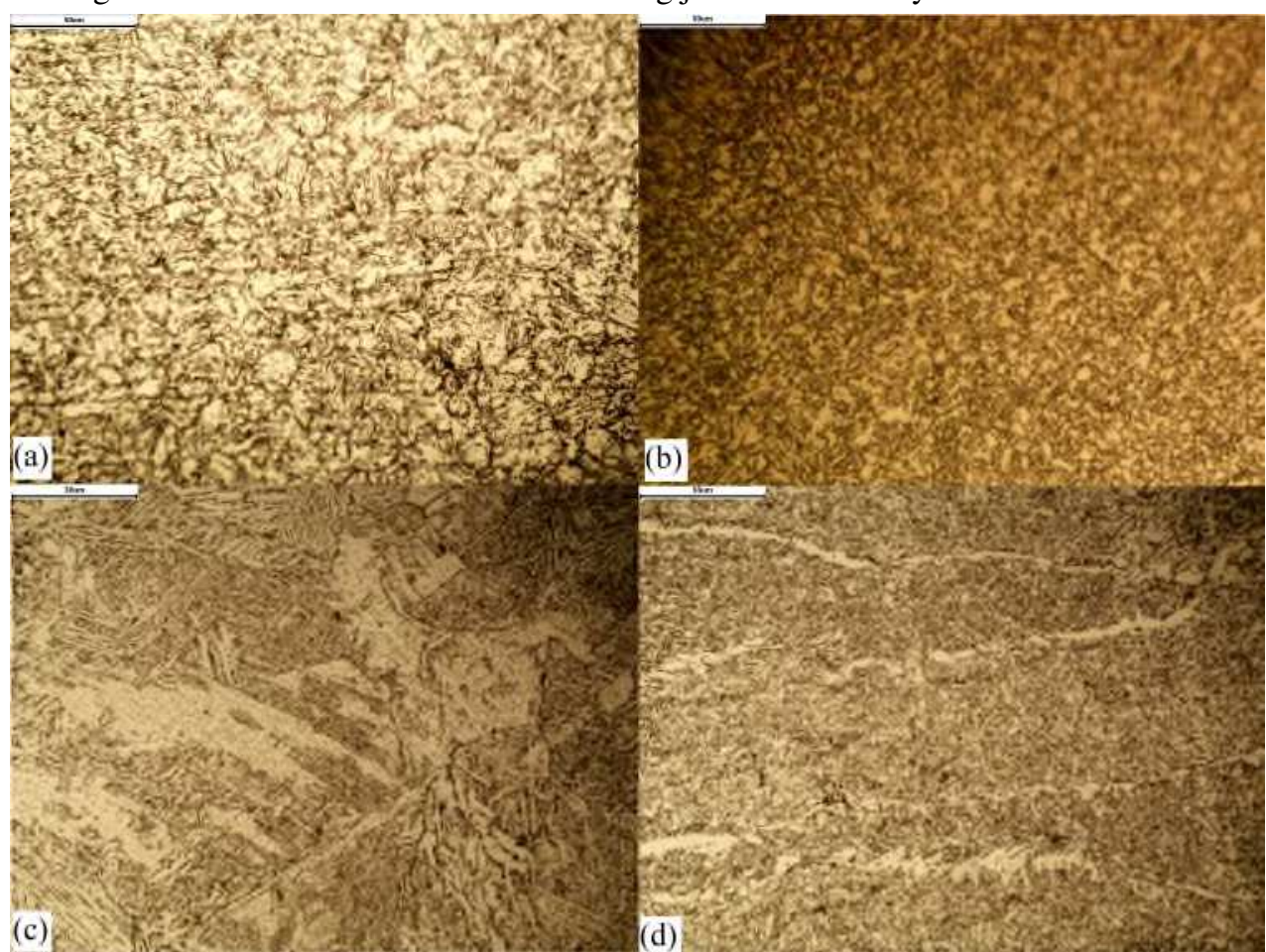

Figure 8. The microstructure of the welding joints (a) the base metal, (b) the fine-grained heat-affected zone, (c) the coarse-grained heat-affected zone, (d) the welding zone.

The welding bead was also cut into smaller samples to test the mechanical properties; the samples were prepared according to Zhao et al. [21]. The geometry of the welding joints was also measured, calculated, and compared with the results predicted by the established models. The errors between the measured values and the predicted values were also calculated. The accordance results are presented in Table 12. The mechanical performances were performed using the tensile shear tests, which were obtained by the load-displacement curve after the tests. The mechanical indexes are composed of the maximum displacement $L$, the peak load $F$, and the failure energy $E$. From Table 12, it certainly can be judged that the mechanical performances of the welding joints are satisfying; the errors of top reinforcement width, top reinforcement height, penetration depth, and bottom reinforcement depth are very tiny, while the value of bottom reinforcement width is considerably large. The reasons may include two aspects, the recommended value of wire feed speed is $4.26 \mathrm{~m} / \mathrm{min}$, while the actual value employed in the verification test is $4.3 \mathrm{~m} / \mathrm{min}$ owing to the accuracy and 
precision of the welding machine for the current study. Additionally, it is worth noting that the predicted $R^{2}$ of the bottom reinforcement width model is about 0.7800 , which implies that $22 \%$ of the data in the whole range is not able to be predicted and navigated precisely by this model. The results produced by the verification test probably locate in this area. All in all, the welding bead profile in different stages is modeled and the effects of the welding process settings on the weld bead can be properly interpreted by the developed models. In addition, the optimization welding parameters were achieved and the results of the verifying test are reasonable. This investigation can be served as a guide for the actual welding production line, although the welding joints produced by the excessive welding heat input should usually be avoided.

Table 12. Results of the verification test.

\begin{tabular}{cccccccccccc}
\hline Items & $A$ & $B$ & $C$ & $W_{l}$ & $R_{l}$ & $P$ & $W_{2}$ & $R_{2}$ & $L$ & $F$ & $E$ \\
\hline Unit & $\mathrm{V}$ & $\mathrm{m} / \mathrm{min}$ & $\mathrm{cm} / \mathrm{min}$ & $\mathrm{mm}$ & $\mathrm{mm}$ & $\mathrm{mm}$ & $\mathrm{mm}$ & $\mathrm{mm}$ & $\mathrm{mm}$ & $\mathrm{kN}$ & $\mathrm{J}$ \\
The calculated value & 17 & 4.26 & 45 & 5.05 & 1.68 & 2.68 & 0.52 & 0.26 & - & - & - \\
The actual value & 17 & 4.3 & 45 & 4.98 & 1.63 & 3.00 & 1.39 & 0.25 & 1.95 & 10.61 & 14.42 \\
Errors & - & - & - & 0.07 & 0.05 & 0.32 & 0.87 & 0.01 & - & - & - \\
\hline
\end{tabular}

\section{Conclusions}

(1) The relationships among the welding parameters (voltage, wire feed speed, and welding speed) and top reinforcement and penetration are quadratic; while the ones for bottom reinforcement are linear.

(2) The welding speed is the most significant variable for bottom reinforcement and top reinforcement height; while the voltage influences the most for the top reinforcement height. In addition, the utmost variable for the penetration depth is the interaction effect of wire feed speed and welding speed.

(3) The effect of the welding speed on the bottom reinforcement is negative; while the effect of wire feed speed is on the same geometric feature is positive. The effects of voltage, welding speed, and wire feed speed on the top reinforcement width and depth, penetration depth transferred from negative to positive when the other two welding parameter are at different levels.

(4) The optimal combination of the welding settings is the voltage of $17 \mathrm{~V}$, wire feed speed is $4.3 \mathrm{~m} / \mathrm{min}$, and welding speed is $45 \mathrm{~cm} / \mathrm{min}$. The accordance welding bead geometry characteristics are top reinforcement width of $4.98 \mathrm{~mm}$, top reinforcement height of $1.63 \mathrm{~mm}$, penetration depth of $3.00 \mathrm{~mm}$, bottom reinforcement width of $1.39 \mathrm{~mm}$, and bottom reinforcement height of $0.25 \mathrm{~mm}$. Its mechanical properties in the tensile shear test are maximum displacement of $1.95 \mathrm{~mm}$, peak load is $10.61 \mathrm{kN}$ and failure energy of $14.42 \mathrm{~J}$.

(5) The weathering steel is made up of pearlite and proeutectoid ferrite; while the welding zone is packed with acicular ferrite, and grain boundary ferrite.

\section{Acknowledgments}

The authors are thankful for the financial support provided by the open projects of State Key Laboratory for Strength and Vibration of Mechanical Structures (SV2019-KF-39).

\section{Conflict of interest}


The authors state no opposing interests.

\section{Availability of data and material}

The data can be offered by the corresponding author under reasonable usage.

\section{Code availability}

The results in this investigation can be simulated through the software for instance Minitab, MODDE, and Design Expert.

\section{References}

[1] Rizvi SA, Ali W (2021) Development of mathematical model and optimization of GMA welding parameters of IS 2062 grade A steel weldments. Frattura ed Integrità Strutturale 15: 84-93.

[2] Meseguer-Valdenebro JL, Portoles A, Matínez-Conesa E (2018) Electrical parameters optimisation on welding geometry in the 6063-T alloy using the Taguchi methods. The International Journal of Advanced Manufacturing Technology 98: 2449-2460.

[3] Kumar S, Singh R (2019) Optimization of process parameters of metal inert gas welding with preheating on AISI 1018 mild steel using grey based Taguchi method. Measurement 148: 106924.

[4] Sailender M, Suresh R, Reddy GC, Venkatesh S (2020) Prediction and comparison of the dilution and heat affected zone in submerged arc welding (SAW) of low carbon alloy steel joints. Measurement 150: 107084.

[5] Saha A, Majumder H (2020) Multi-attribute optimisation of submerged arc welding process parameters using Taguchi GRA-PCA hybrid approach. Australian Journal of Mechanical Engineering: DOI: 10.1080/14484846.2020.1790476.

[6] Korra NN, Vasudevan M, Balasubramanian KR (2015) Multi-objective optimization of activated tungsten inert gas welding of duplex stainless steel using response surface methodology. The International Journal of Advanced Manufacturing Technology 77: 67-81.

[7] Martinez-Conesa EJ, Egea JA, Miguel V, Toledo C, Meseguer-Valdenebro JL (2017) Optimization of geometric parameters in a welded joint through response surface methodology. Construction and Building materials 154: 105-114.

[8] Sharma P, Chattopadhyaya S, Singh NK (2019) Optimization of gas metal arc welding parameters to weld AZ31B alloy using response surface methodology. Materials Research Express 6: 106569.

[9] Moghaddam MA, Golmezergi R, Kolahan F (2016) Multi-variable measurements and optimization of GMAW parameters for API-X42 steel alloy using a hybrid BPNN-PSO approach. Measurement 92: 279-287.

[10] Nalajam P, Varadarajan R (2021) Experimental and theoretical investigations on cold metal transfer welds using neural networks: a computational model of weld geometry. Experimental Techniques: https://doi.org/10.1007/s40799-021-00451-7.

[11] Venkatarao K (2021) The use of teaching-learning based optimization technique for optimizing weld bead geometry as well as power consumption in additive manufacturing. 
Journal of Cleaner Production 279: 123891.

[12] Sivasakthivel PS, Sudhakaran R (2020) Modelling and optimisation of welding parameters for multiple objectives in pre-heated gas metal arc welding process using nature instigated algorithms. Australian Journal of Mechanical Engineering 18: S76-S87.

[13] Jorge VL, Scotti FM, Reis RP, Scotti A (2020) The potential of wire feed pulsation to influence factors that govern weld penetration in GMA welding. The International Journal of Advanced Manufacturing Technology 110: 2685-2701.

[14] Zhang Z, Xue J (2019) Profile map of weld beads and its formation mechanism in gas metal arc welding. Metals 9: 146.

[15] Chandrasekaran RR, Benoit MJ, Barrett JM, Gerlich AP (2019) Multi-variable statistical models for predicting bead geometry in gas metal arc welding. The International Journal of Advanced Manufacturing Technology 105: 1573-1584.

[16] Zhao D, Osipov A, Bezmelnitsyn A, Vdonin N, Liang D (2021) Statistical modeling and optimization of the resistance welding process with simultaneous expulsion magnitude consideration for high-strength low alloy steel. The International Journal of Advanced Manufacturing Technology 113: 1173-1189.

[17] Sridhar PV, Biswas P, Mahanta P (2020) Effect of process parameters on bead geometry, tensile and microstructural properties of double-sided butt submerged arc welding of SS 304 austenitic stainless steel. Journal of the Brazilian Society of Mechanical Sciences and Engineering 42: 1-5.

[18] Esfahani MM, Farzadi A, Zaree SA (2018) Effect of welding speed on gas metal arc weld pool in commercially pure aluminum: theoretically and experimentally. Russian Journal of Non-Ferrous Metals 59: 82-92.

[19] Ayaz M, Khandaei M, Vahidshad Y (2021) Design and optimization of an integrated multi-layer coil for decreasing the discharge energy in electromagnetic welding using numerical and experimental methods. Welding in the World 65: 211-227.

[20] Shen S, Oguocha IN, Yannacopoulos S (2012) Effect of heat input on weld bead geometry of submerged arc welded ASTM A709 Grade 50 steel joints. Journal of Materials Processing Technology 212: 286-94.

[21] Zhao D, Bezgans Y, Vdonin N, Du W (2021) The use of TOPSIS-based-desirability function approach to optimize the balances among mechanical performances, energy consumption, and production efficiency of the arc welding process. The International Journal of Advanced Manufacturing Technology 112: 3545-3559. 


\section{Figures}

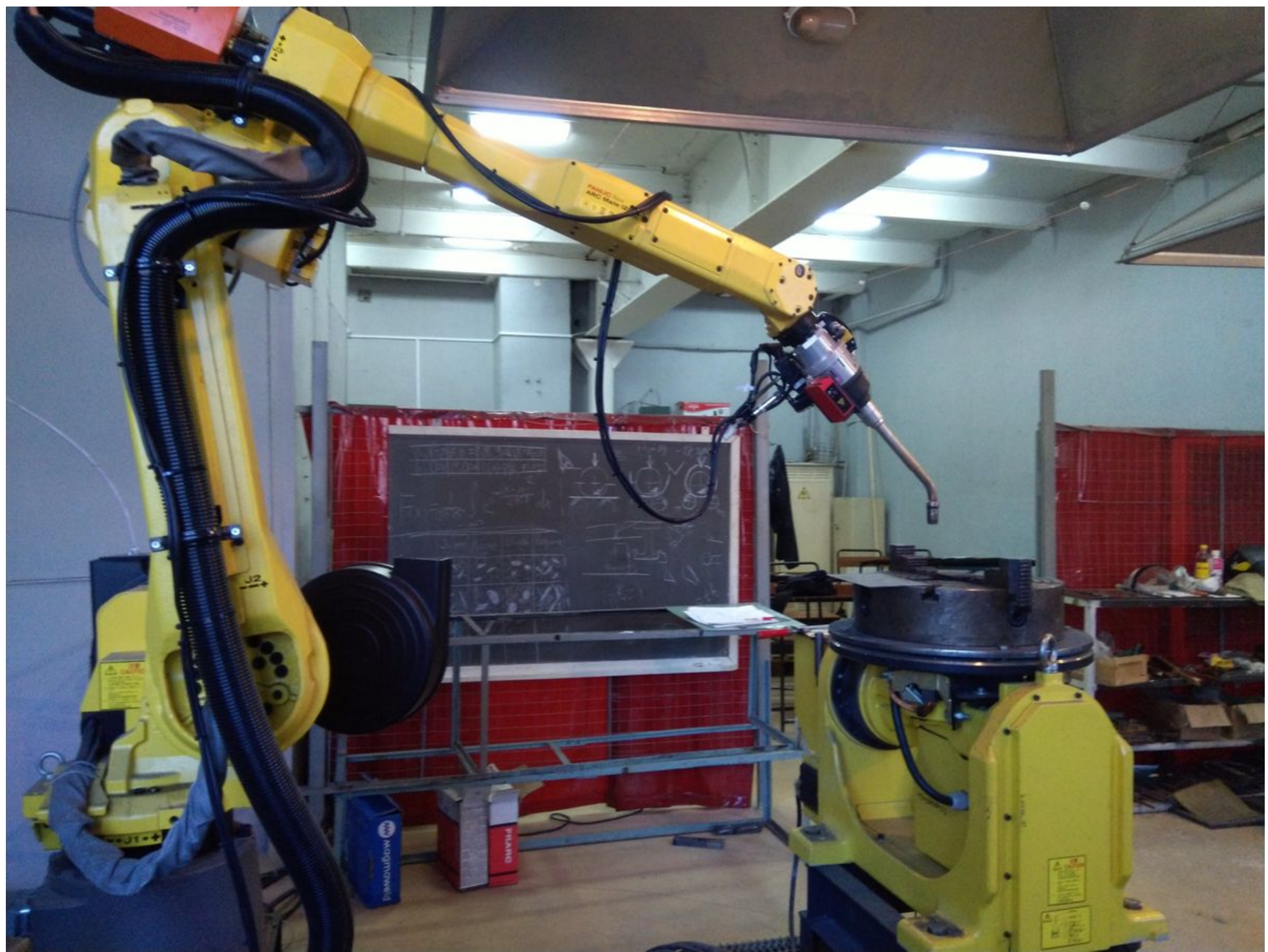

\section{Figure 1}

The welding machine employed in this investigation.

(a)

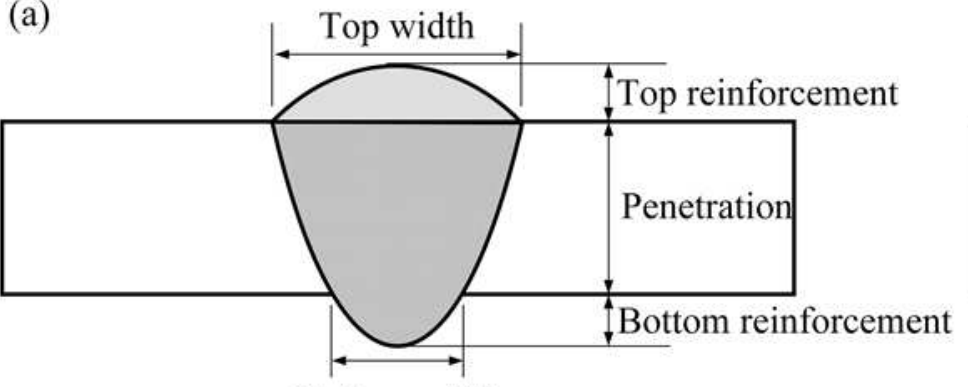

Bottom width (b)

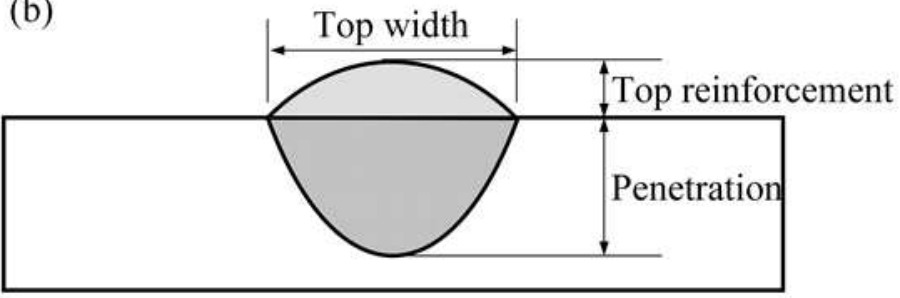

Figure 2

A typical welding bead (a) over-penetrated (b) insufficient-penetrated. 
(a)

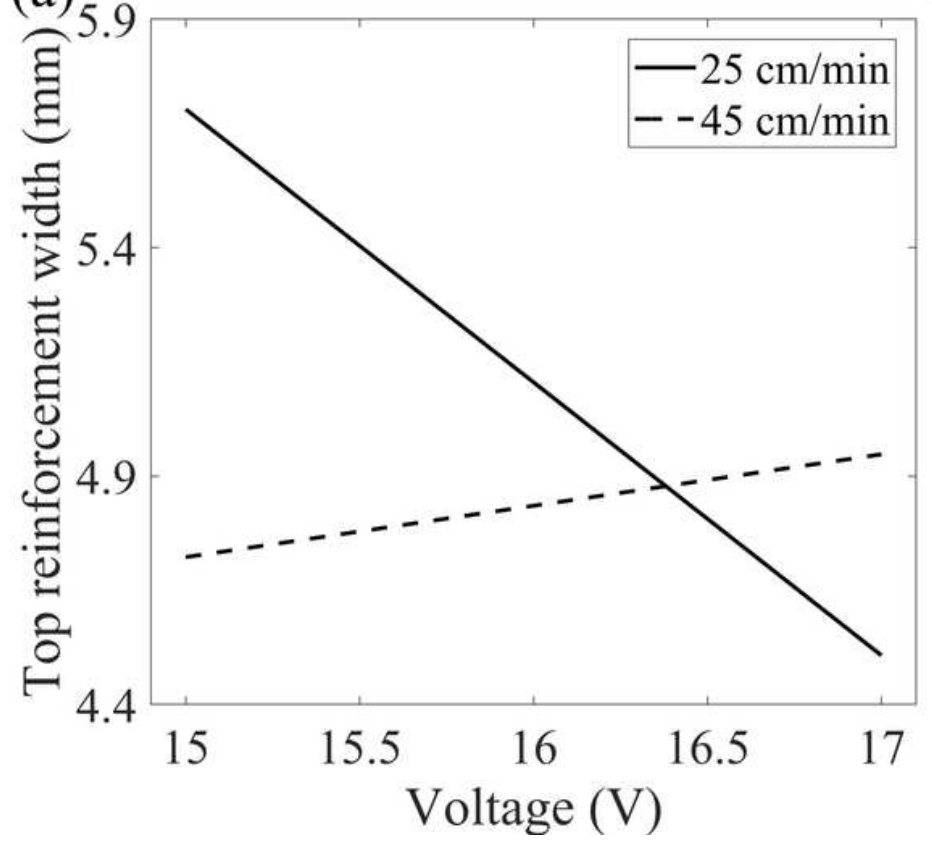

(b)

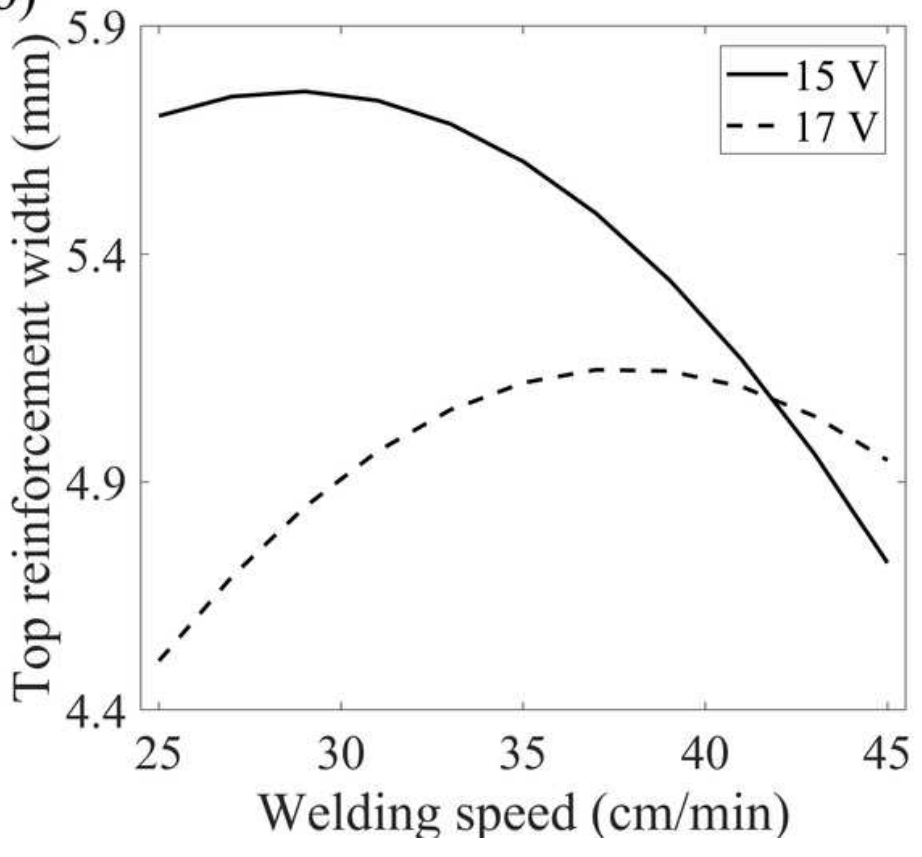

Figure 3

The effects of voltage and welding speed on the top reinforcement width ( $B=4.5 \mathrm{~m} / \mathrm{min}$ ).
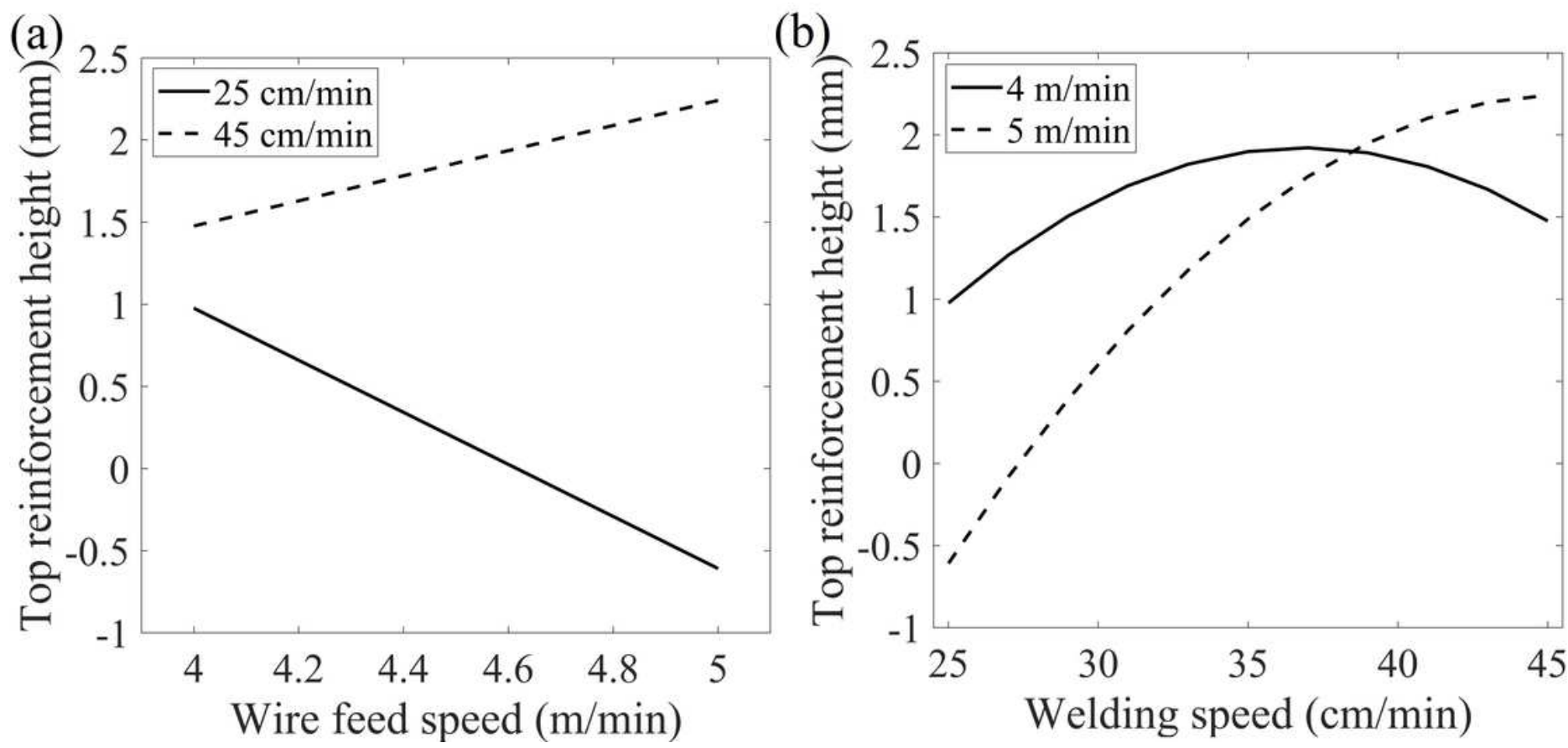

Figure 4

The effects of wire feed speed and welding speed on the top reinforcement height $(A=16 \mathrm{~V})$. 

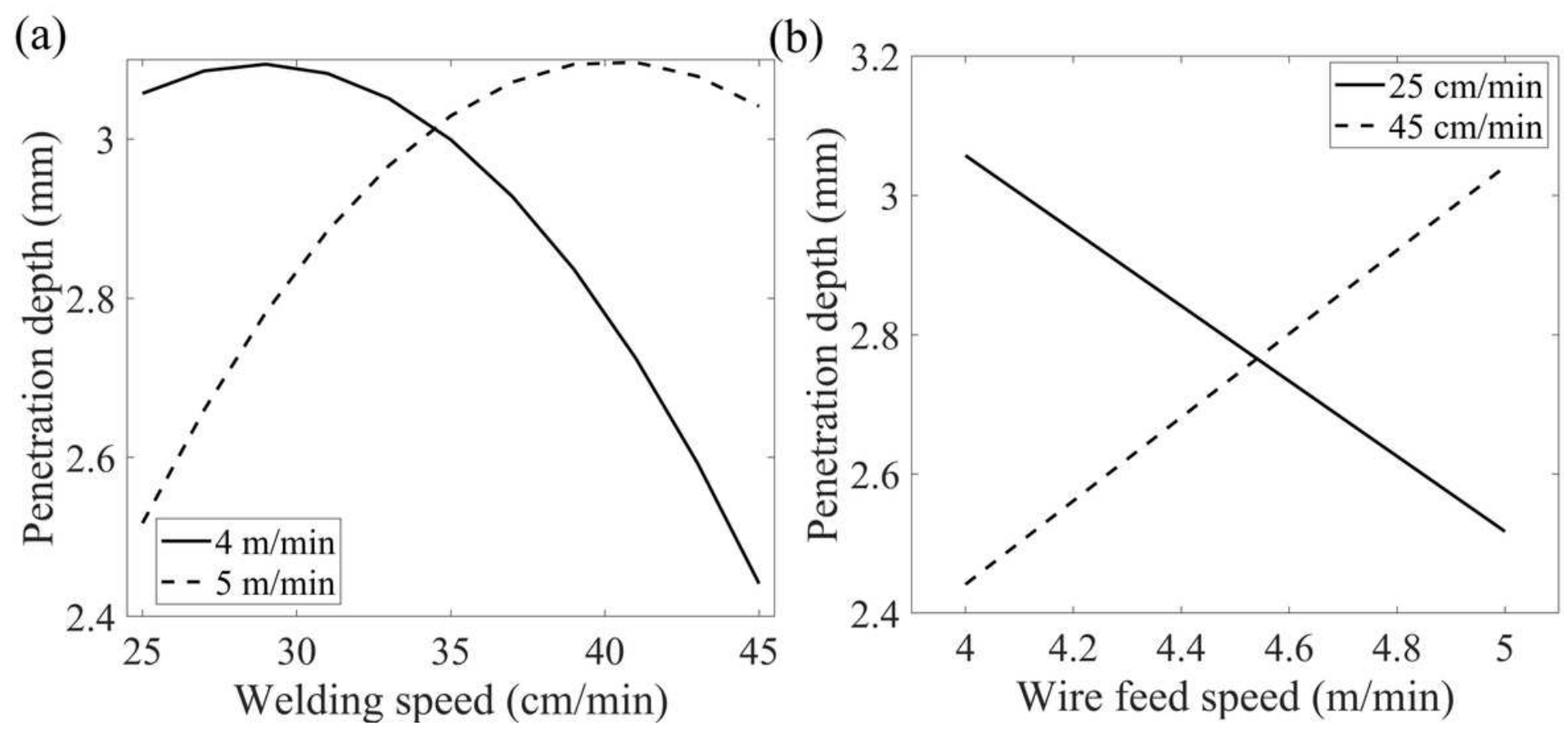

Figure 5

The effects of welding speed and wire feed speed on the penetration depth $(A=16 \mathrm{~V})$.
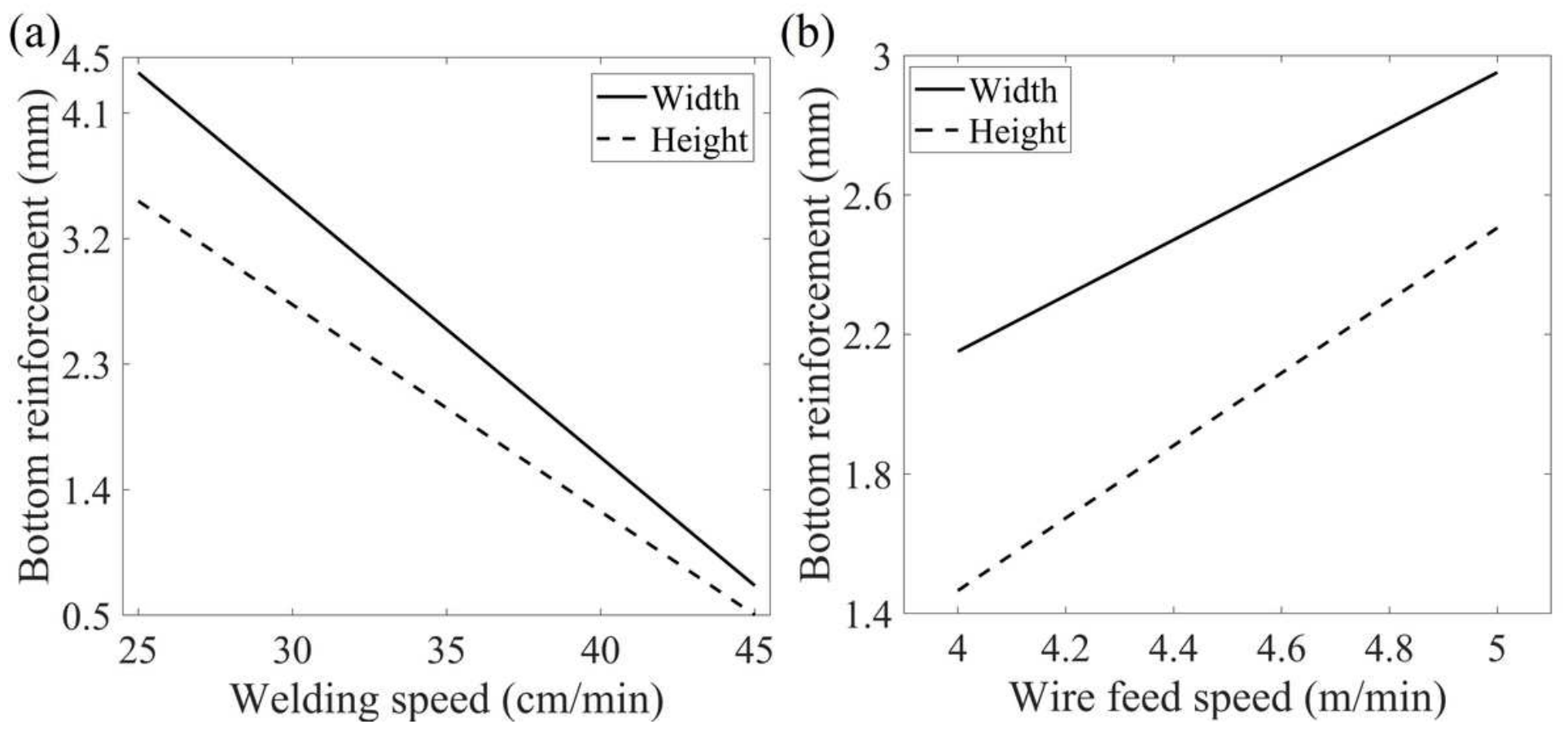

Figure 6

The effects of welding speed and wire feed speed on the bottom reinforcement size $(A=16 \mathrm{~V})$. 


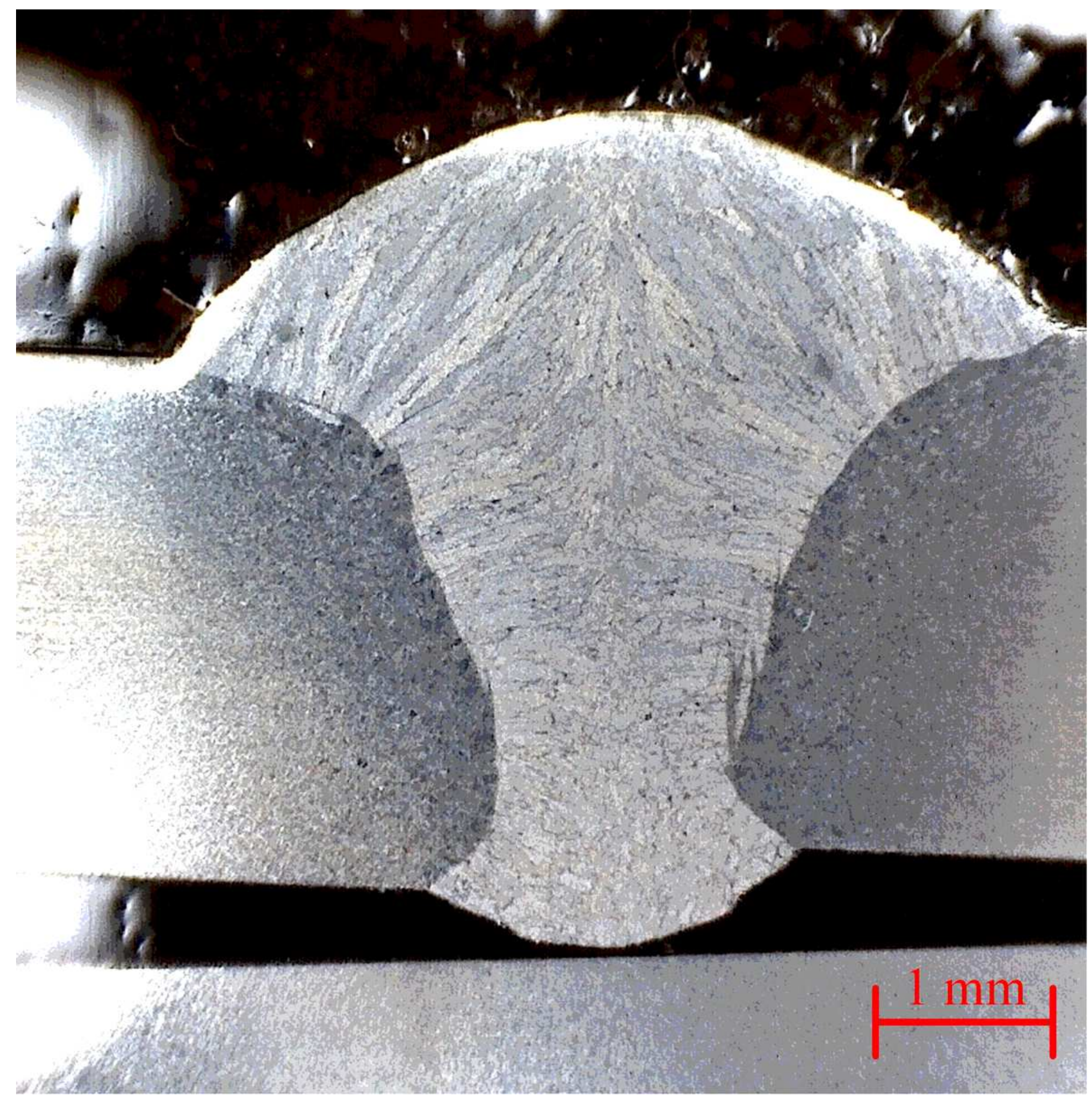

Figure 7

The macrostructure of the welding joints obtained by the verification test. 


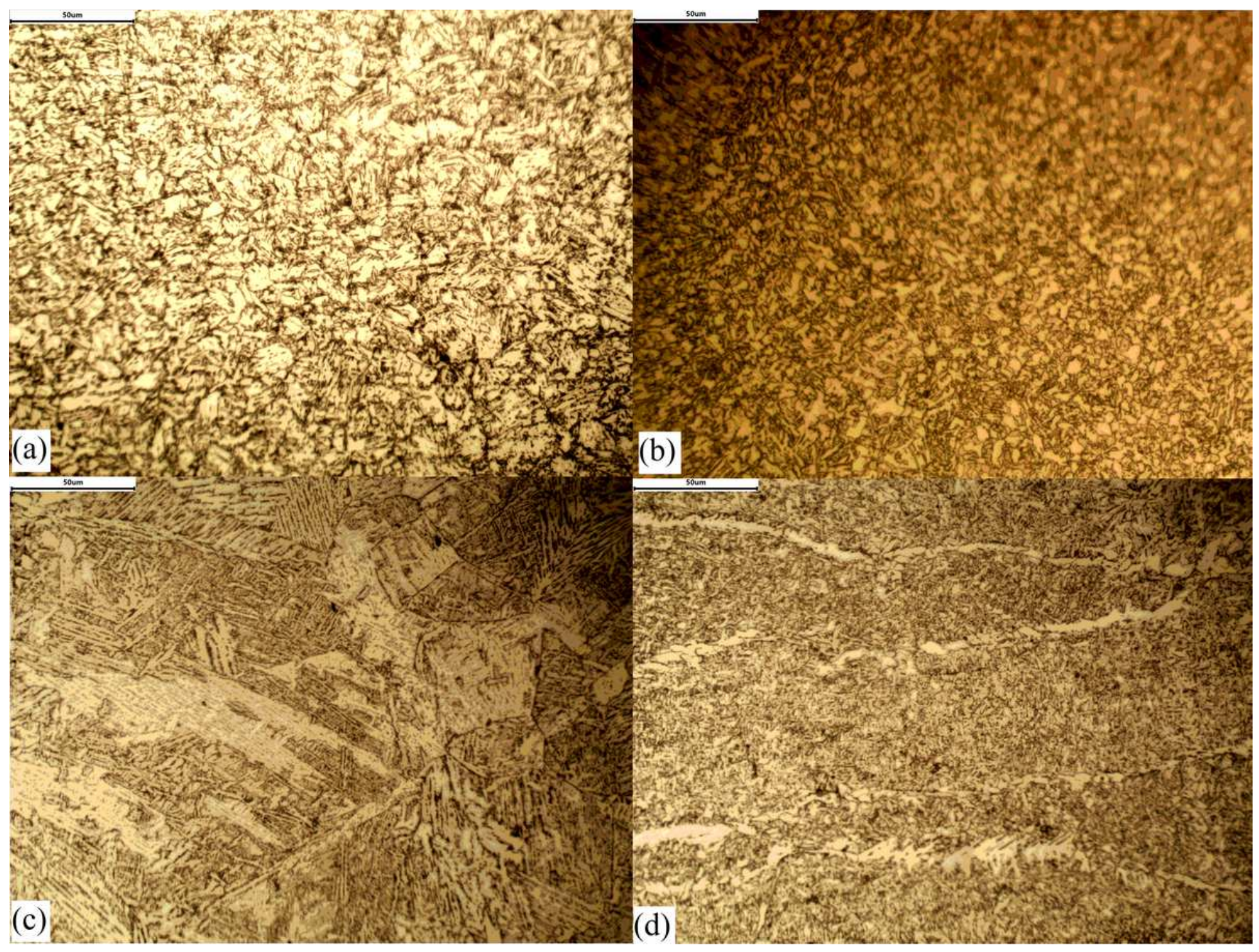

Figure 8

The microstructure of the welding joints (a) the base metal, (b) the fine-grained heat-affected zone, (c) the coarse-grained heat-affected zone, (d) the welding zone. 